National Marine

Fisheries Service

Fishery Bulletin

Spencer F. Baird

NOAA

Abstract-The limited resources and high species diversity associated with coastal fisheries present challenges to their effective management. Datalimited approaches to assessment of stocks are often used in these situations, but most assessments require basic life history information that is often unavailable. We expanded a stepwise meta-analytical approach in which statistical relationships between key life history traits are used to estimate parameters related to growth, maturity, and longevity. This approach was originally devised for 6 fish families and has been successfully implemented in the assessments of data-poor reef fish species in Hawaii and Guam. We expanded this approach to groupers, wrasses, grunts, and sharks and, here, present an $R$ package that greatly simplifies its implementation. Further, we tested this expansion by selecting a species from each of these taxa and compared results from use of the stepwise approach to results from life history studies. Our results indicate agreement between the probability distributions from our stepwise approach and those from previous studies. Distributions from the stepwise simulation had higher variability but reasonable accuracy in estimating missing values of life history parameters. We also tested our approach against another meta-analytical life history approach that was recently published (and made available as the $\mathrm{R}$ package FishLife) and found our stepwise approach to be generally more precise and accurate.

Manuscript submitted 5 June 2020. Manuscript accepted 30 April 2021. Fish. Bull. 119:77-92 (2021). Online publication date: 4 June 2021. doi: 10.7755/FB.119.1.9

The views and opinions expressed or implied in this article are those of the author (or authors) and do not necessarily reflect the position of the National Marine Fisheries Service, NOAA.

\title{
An extension of the stepwise stochastic simulation approach for estimating distributions of missing life history parameter values for sharks, groupers, and other taxa
}

\author{
Kenneth A. Erickson (contact author) ${ }^{1,3}$ \\ Marc O. Nadon ${ }^{2,3}$ \\ Email address for contact author: kerick6@Isu.edu \\ ${ }^{1}$ Department of Oceanography and Coastal Sciences \\ Louisiana State University \\ Energy Coast and Environment Building \\ 93 South Quad Drive, Room 2263 \\ Baton Rouge, Louisiana 70803 \\ 2 Joint Institute for Marine and Atmospheric Research \\ School of Ocean and Earth Science and Technology \\ University of Hawaii at Manoa \\ 1000 Pope Road \\ Honolulu, Hawaii 96822 \\ ${ }^{3}$ Pacific Islands Fisheries Science Center \\ National Marine Fisheries Service, NOAA \\ 1845 Wasp Boulevard, Building 176 \\ Honolulu, Hawaii 96818
}

Coastal fisheries provide sustenance and a source of income for millions of people across the globe (Kronen et al., 2010; Symes et al., 2015; FAO, 2016). These fisheries typically target hundreds of species from different taxa, and this high species diversity makes the management of these fisheries challenging (Ault et al., 2014). In addition, resources for fisheries research and management are often lacking, resulting in a paucity of data that limits the development of well-informed management plans (Fenner, 2012; Gilman et al., 2014; Hilborn and Ovando, 2014; Berkson and Thorson, 2015). Assessing these fisheries is further limited by a lack of long-term catch and fishing effort records needed to implement certain stock assessment models.

To compensate for shortcomings, recent stock assessment methods have been focused on the use of cost-efficient length data (Ault et al., 1998, 2008; Gedamke and Hoenig, 2006; Nadon et al., 2015; Hordyk et al., 2016; Rudd and Thorson, 2018; Nadon, 2019). These length-based methods require life history information related to growth: parameters of the von Bertalanffy growth function (von Bertalanffy, 1938), the asymptotic length $\left(L_{\infty}\right)$ and growth coefficient $(K)$; natural mortality $(M)$; and length at maturity $\left(L_{\text {mat }}\right.$, the length at which $50 \%$ of individuals are mature). However, species-specific information on life history traits is missing for as many as $83 \%$ of exploited stocks globally (Froese and Binohlan, 2000). To address this issue, Nadon and Ault (2016) developed a stepwise stochastic simulation approach in which a local estimate of maximum length $\left(L_{\max }\right)$ and statistical relationships between life history parameters are used to estimate this missing information. 
Fundamental relationships between life history traits in fish species were first observed by Beverton and Holt (1959). They pointed out that $M$ and $K$ are typically related by a ratio close to 1.5 , that the ratio of $L_{\text {mat }}$ to $L_{\infty}$ is typically around 0.66 , and that $L_{\infty}$ and $K$ have a negative power relationship that has a general form of $L_{\infty} \sim K^{-\mathrm{h}}$, with a shape parameter $(h)$, which is typically around 0.5. These relationships are referred to as Beverton-Holt invariants in the literature (Charnov, 1993) and are likely conserved through natural selection because of their link with the maximization of offspring (Beverton and Holt, 1959; Jensen, 1996, 1997; Charnov, 2008). Results of recent meta-analytical studies indicate that ratios differ significantly between taxa and are therefore better studied within taxa (Hordyk et al., 2015; Nadon and Ault, 2016; Thorson et al., 2017).

Relationships of life history traits are useful for the estimation of missing life history parameter values by relating ones, such as $M$, for which information is elusive to ones, such as $L_{\infty}$ and $K$, for which values are more easily obtained (Pauly, 1980), or by relating $L_{\max }$ to other length parameters (e.g., $L_{\text {mat }}$ ) (Froese and Binohlan, 2000, 2003; Jarić and Gačić, 2012). The aim of these studies was mainly to generate missing estimates for single parameters, and these studies were not taxon-specific, limiting their utility by ignoring the complex multivariate distribution between key life history parameters. As a solution, Nadon and Ault (2016) presented an approach that involves the use of Monte Carlo simulation draws and several regression model steps between life history parameters for 6 fish families. Their approach allows for complex relationships between parameters, while maintaining a multivariate error structure. This approach is analogous to the method in which a sequence of regressions is used for multiple imputation of missing data (Raghunathan et al., 2001; van Buuren, 2007; Ellington et al., 2015).

Nadon and Ault (2016) determined family-specific relationships between key life history traits after an extensive literature review for 6 families of coastal fish species: surgeonfishes, jacks, snappers, emperors, goatfishes, and parrotfishes. Peer-reviewed data-limited assessments of stocks in Hawaii (Nadon, 2017) and Guam (Nadon, 2019) have already been implemented by using this approach. The goal of our study was to extend the approach from Nadon and Ault (2016) to 3 additional families of tropical coastal fish species, groupers (Serranidae), wrasses (Labridae), and grunts (Haemulidae), as well as to sharks from the orders Carcharhiniformes and Lamniformes. We acknowledge that taxonomy is an evolving field and with new information can come new evidence for reclassification. Recently, this evolution has touched groupers with proposals to move the subfamily Epinephelinae, including the genus Epinephelus, under the family Epinephelidae instead of under the family Serranidae (Craig and Hastings, 2007; Smith and Craig, 2007; Ma and Craig, 2018). Although some classifications put grouper taxa under Epinephelidae instead of Serranidae, for the purposes of this study, we used Serranidae as the family name for species of Epinephelinae and other grouper species.
Additionally, we tested this approach against those of life history studies and against the approach of Thorson et al. (2017) as applied in their $R$ package FishLife. We also developed, and present here, a new $\mathrm{R}$ package, StepwiseLH, that simplifies the implementation of the stepwise approach for all 10 included taxonomic groups. Our results will improve the capability to conduct stock assessments for these taxonomic groups in data-limited situations.

\section{Materials and methods}

\section{Details of the stepwise approach}

The approach presented in Nadon and Ault (2016) involves a series of regression models in which relationships between life history parameters are used to sequentially estimate missing values for life history parameters from the previously estimated parameters (Fig. 1, Table 1). Note that the regression models that relate these parameters

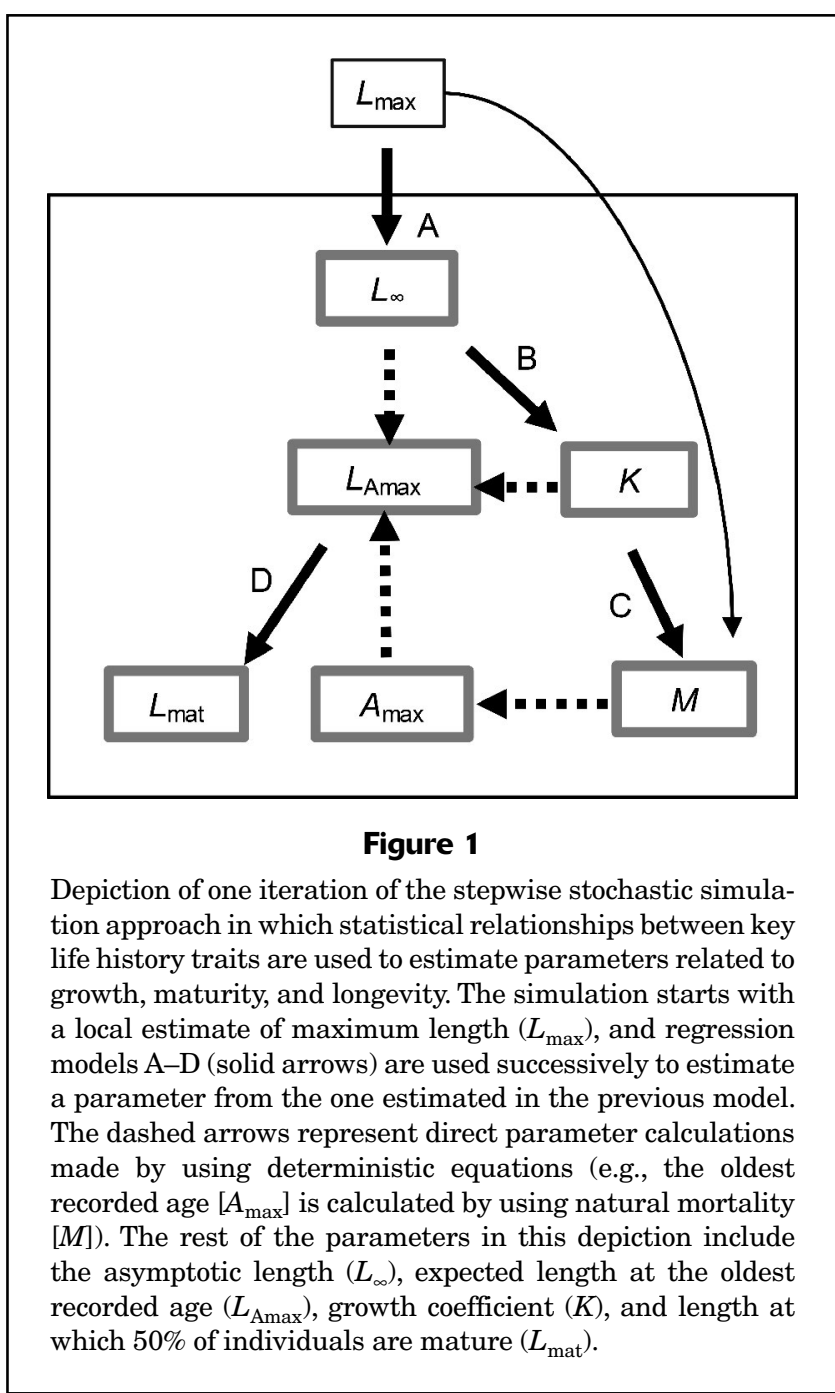




\section{Table 1}

List of life history parameters, with their definitions, used in the stepwise stochastic simulation to produce missing estimates of life history parameters for groupers (Serranidae), wrasses (Labridae), grunts (Haemulidae), and sharks from the orders Carcharhiniformes and Lamniformes. All lengths used for these parameters are total lengths.

\begin{tabular}{ll} 
Parameter & Definition \\
\hline$L_{\text {Amax }}$ & $\begin{array}{l}\text { Expected length at the oldest recorded age } \\
\text { (also known as } L_{\lambda} \text { ) }\end{array}$ \\
$L_{\text {mat }}$ & $\begin{array}{l}\text { Length at which } 50 \% \text { of individuals reach } \\
\text { maturity }\end{array}$ \\
$L_{\max }$ & $\begin{array}{l}\text { Longest length in a growth study or 99th } \\
\text { percentile of lengths in a population survey }\end{array}$ \\
$L_{\infty}$ & $\begin{array}{l}\text { Asymptotic length (expected length at } \\
\text { infinite age) }\end{array}$ \\
$K$ & $\begin{array}{l}\text { Brody growth coefficient of the von Berta- } \\
\text { lanffy growth function }\end{array}$ \\
$A_{0}$ & $\begin{array}{l}\text { Theoretical age at which length equals zero } \\
A_{\max }\end{array}$ \\
$M$ & $\begin{array}{l}\text { Oldest recorded age (i.e., longevity) } \\
\text { Instantaneous natural mortality rate }\end{array}$
\end{tabular}

are not universal but specific to taxonomic groups (e.g., snappers). The 4 models (A-D) of statistical relationships between life history parameters used in the stepwise approach (Fig. 1) are, sequentially, as follows:

$$
\begin{aligned}
\text { A) } L_{\infty}=b_{0}+ & b_{1} L_{\max }+\varepsilon \text { (linear function); } \\
\text { B) } \log (K)= & \log \left(b_{2}\right)+b_{3} \log \left(L_{\infty}\right)+\varepsilon \\
& \text { (power function) or }
\end{aligned}
$$

$\log (K)=\log \left(b_{2}\right)+b_{3} L_{\infty}+\varepsilon$ (exponential function);

$$
\text { C) } \begin{aligned}
\log (M)= & \log \left(b_{4}\right)+b_{5} \log (K)+b_{6} \log \left(L_{\max }\right) \\
& +\varepsilon(\text { power function }) \text { or } \\
\log (M)= & \log \left(b_{4}\right)+b_{5} K+b_{6} L_{\max } \\
& +\varepsilon(\text { exponential function }) ; \text { and }
\end{aligned}
$$

D) $L_{\text {mat }}=b_{7}+b_{8} L_{\mathrm{Amax}}+\varepsilon$ (linear function),

where $\varepsilon=$ a normally distributed error term (note: this error term can also be lognormally distributed for models $A$ and $D$, if the residuals pattern indicates a lognormal distribution;

$b=$ a model coefficient, either the slope or intercept; and

$L_{\mathrm{Amax}}=$ the expected length at the oldest recorded age $\left(A_{\max }\right)$.

These 4 models are used in the stepwise approach to generate probability distributions of the parameters $L_{\infty}$, $K, L_{\text {mat }}$, and $M$ as follows. First, a local estimate of $L_{\max }$ is obtained from a data set of representative lengths (note: we recommend using the 99th percentile of the length data set to avoid inclusion of an outlier $L_{\max }$ value and bootstrapping this data set to incorporate variability in $L_{\text {max }}$ ). Second, this $L_{\max }$ value is entered into model A (also referred to as $L_{\max } \sim L_{\infty}$ ) to obtain the expected $L_{\infty}$ value at a given $L_{\text {max }}$. Third, a single random $L_{\infty}$ value is sampled from the error distribution of $L_{\infty}$ at that specific location on the linear regression model. Fourth, this random $L_{\infty}$ value is used in model $\mathrm{B}$ to obtain the expected $K$ value for this given $L_{\infty}$ value. A random $K$ value is then drawn from the error distribution at this location. Fifth, this random $K$ value is entered into model C, which also includes the starting $L_{\max }$ value, to obtain the expected $M$ value. A random $M$ estimate is sampled at this location in the regression model.

Next, the previously estimated random $L_{\infty}, K$, and $M$ values are entered into the von Bertalanffy growth function to obtain $L_{\text {Amax }}$, also known as $L_{\lambda}$ in Nadon and Ault (2016):

$$
L_{\mathrm{Amax}}=L_{\infty}\left(1-e^{-\mathrm{K}\left(A_{\max }-A_{0}\right)}\right),
$$

where $A_{0}=$ the age at length zero (a fitting parameter of the von Bertalanffy equation that is fixed at -0.6 in the stepwise approach, its overall mean value).

The parameter $A_{\max }$ is obtained by using the relationship of longevity to $M$ presented in Hoenig (1983) and in Hewitt and Hoenig (2005), under the assumption that survivorship of a cohort at the oldest recorded age $(S)$ was $5 \%$, with this formula:

$$
M=\frac{-\ln (0.05)}{A_{\max }} .
$$

Note that when implementing the stepwise approach, users can calculate an $M$ estimate under a different equation or $S$ value and are not bound to use an $S$ of 0.05 . The flexibility of natural mortality estimates is discussed further in the "Discussion" section.

Finally, the $L_{\text {Amax }}$ value obtained by using Equation 7 is entered into model $\mathrm{D}$ to obtain the expected $L_{\text {mat }}$ value, and a random $L_{\text {mat }}$ is drawn from the error distribution at this location on the model D curve. This stepwise procedure is repeated several thousand times to obtain a multivariate probability distribution of all 4 life history parameters that can then be directly used in various stock assessment models. Uncertainty of regression model coefficients was included at every step by drawing a random set of regression coefficients from a normal multivariate distribution, defined by the variance-covariance matrix associated with these regression coefficients. Values of the variance-covariance matrix are presented in Table 2, along with model coefficients and residual error distributions.

\section{Literature review and model fit for new taxa}

The previous section describes how the stepwise procedure is implemented by using predictions from a series of 4 previously established regression models. Regression models used in each step are specific to individual taxonomic groups (e.g., parrotfishes, snappers, or jacks). To create 4 new family-specific models, we first reviewed the literature to generate new data sets of life history traits. 


\section{Table 2}

Model functional form, error probability distribution, and variance-covariance matrix of regression coefficients for models A-D of statistical relationships between key life history parameters for 3 families of tropical coastal fish species and for sharks from the orders Carcharhiniformes and Lamniformes. For each taxon, the first line presents model functional forms and error distributions in brackets. Models are linear $\left(\mathrm{L} ; Y=b_{0}+b_{1} \ldots X\right)$ and power $\left(\mathrm{P} ; \log Y=b_{0}+b_{1} \ldots \log X\right)$ functions. Error distribution types are normal $(\mathrm{N})$ and lognormal (LN). The first line also shows regression coefficients followed by the standard deviation for each distribution, given as the last value in the line. The second line presents the variance-covariance matrix of the regression parameters for 1-variable models ( $b_{0}$ variance, $b_{1}$ variance, and $b_{0}-b_{1}$ covariance) and 2 -variable models $\left(b_{0}\right.$ variance, $b_{1}$ variance, $b_{2}$ variance, $b_{0}-b_{1}$ covariance, $b_{0}-b_{2}$ covariance, and $b_{1}-b_{2}$ covariance). The models relate the following parameters: the asymptotic length $\left(L_{\infty}\right)$, maximum length $\left(L_{\max }\right)$, growth coefficient $(K)$, natural mortality $(M)$, length at which $50 \%$ of individuals are mature $\left(L_{\text {mat }}\right)$, and the expected length at the oldest recorded age $\left(L_{\text {Amax }}\right)$. TL=total length.

\begin{tabular}{|c|c|c|c|c|}
\hline \multirow[b]{2}{*}{ Taxon } & \multicolumn{4}{|c|}{ Model } \\
\hline & (A) $L_{\infty} \sim L_{\max }$ & (B) $K \sim L_{\infty}$ & (C) $M \sim K+L_{\max }$ & (D) $L_{\mathrm{mat}} \sim L_{\mathrm{Amax}}$ \\
\hline Haemulidae & $\begin{array}{c}{[\mathrm{L}, \mathrm{N}]-29.3,1.08,53.5} \\
\quad 2170,0.0892,-4.15\end{array}$ & $\begin{array}{l}{[\mathrm{P}, \mathrm{LN}] 4.21,-0.87,0.33} \\
\quad 1.86,0.05,-0.3\end{array}$ & $\begin{array}{l}\text { [P,LN] 6.11, 0.11, }-1.28,0.39 \\
\quad 8.05,0.11,0.25,-0.47 \\
\quad-1.42,0.0956\end{array}$ & $\begin{array}{l}{[\mathrm{L}, \mathrm{N}] 101,0.5,31.4} \\
\quad 1420,0.00787,-3.09\end{array}$ \\
\hline Labridae & $\begin{array}{c}{[\mathrm{L}, \mathrm{N}]-61.3,1.08,53.8} \\
976,0.00377,-1.67\end{array}$ & $\begin{array}{r}{[\mathrm{P}, \mathrm{LN}] 4.15,-0.94,0.5} \\
1.54,0.0453,-0.262\end{array}$ & $\begin{array}{l}{[\mathrm{P}, \mathrm{LN}]-2.61,0.64,0.27,0.42} \\
\quad 2.7,0.0587,0.1,-0.28 \\
\quad-0.515,0.06\end{array}$ & $\begin{array}{l}{[\mathrm{L}, \mathrm{LN}] 70,0.27,0.28} \\
\quad 1130,0.0074,-2.54\end{array}$ \\
\hline $\begin{array}{l}\text { Serranidae: small } \\
\quad(\leq 100 \mathrm{~cm} \text { TL })\end{array}$ & $\begin{array}{l}{[\mathrm{L}, \mathrm{N}]-19.7,0.97,60.9} \\
552,0.0017,-0.9\end{array}$ & $\begin{array}{r}{[\mathrm{P}, \mathrm{LN}] 3.69,-0.83,0.49} \\
0.42,0.0104,-0.0653\end{array}$ & $\begin{array}{l}{[\mathrm{P}, \mathrm{LN}] 0.73,0.23,-0.36,0.35} \\
\quad 0.404,0.00774,0.0125 \\
\quad-0.0296,-0.07,0.0065\end{array}$ & $\begin{array}{r}{[\mathrm{L}, \mathrm{LN}] 53.6,0.49,0.13} \\
193,0.000709,-0.32\end{array}$ \\
\hline $\begin{array}{l}\text { Serranidae: large } \\
\text { (>100 cm TL })\end{array}$ & $\begin{array}{l}{[\mathrm{L}, \mathrm{N}] 5.11,0.92,95.4} \\
\quad 15,179,0.0081,-10.8\end{array}$ & - & - & - \\
\hline Sharks & $\begin{array}{l}{[\mathrm{L}, \mathrm{N}] 95.9,1.02,217} \\
\quad 10,100,0.00165,-3.65\end{array}$ & $\begin{array}{c}{[\mathrm{P}, \mathrm{LN}] 6.77,-1.15,0.47} \\
1.91,0.0327,-0.25\end{array}$ & $\begin{array}{l}{[\mathrm{P}, \mathrm{LN}] 3.65,0.11,-0.69} \\
\quad 0.210 .59,0.00591,0.013 \\
\quad-0.0336,-0.0862,0.00603\end{array}$ & $\begin{array}{c}{[\mathrm{L}, \mathrm{LN}]-17.4,0.79,0.12} \\
\quad 5080,0.00265,-3.33\end{array}$ \\
\hline
\end{tabular}

An extensive literature review was conducted by using several sources and collections (e.g., FishBase, Froese and Pauly, 2017; the libraries at the NOAA Pacific Islands Fisheries Science Center and North Carolina State University; and general Internet search tools) to find published studies related to growth $\left(L_{\infty}\right.$ and $\left.K\right)$, maturity $\left(L_{\text {mat }}\right)$, and longevity ( $A_{\max }$, from which $M$ is derived). Values of $L_{\max }$ were obtained from the same growth studies from which values of $L_{\infty}$ and $K$ were obtained, by taking the largest observed length in each study.

We originally included the following families in our literature review: Haemulidae (grunts), Holocentridae (squirrelfishes), Labridae (wrasses), Serranidae (groupers), and Siganidae (rabbitfishes), as well as sharks from various families. Groupers and wrasses include hundreds of small-bodied species (i.e., $<10 \mathrm{~cm}$ total length), with nonexistent life history information, that we excluded from our search. We excluded species of groupers from the genus Anthias and species of wrasses from several genera, such as Cirrhilabrus, Halichoeres, Labroides, and Pseudojuloides. These species are characterized by extremely small body sizes, and their growth, maturity, and longevity traits are unlikely to have the same relationships as the traits of larger species in the same families. Researchers should not use the stepwise approach on species from these genera, even if life history studies for these species are available. In addition, the only family of sharks that had enough life history information to run an independent statistical analysis was Carcharhinidae, and almost all of the shark studies we found were on species from the orders Carcharhiniformes and Lamniformes. We therefore defined the shark group in our study described here as a group containing species from these 2 orders only.

We examined information available for 1134 species in these taxonomic groups, but we found published growth and maturity values for only 115 of those species (Table 3; for a list of these species and the literature used as sources of life history information, see Supplementary Table), highlighting the paucity of information available for assessment of these species. Because of a lack of published studies, we were unable to extend the approach of Nadon and Ault (2016) to squirrelfishes and rabbitfishes because only 2 and 6 species in these families had published life history data, respectively.

Raw data sets were generally unavailable from the studies in our literature review. We therefore had to rely on the fitted growth and maturity parameters from the von Bertalanffy growth function and on the logistic maturity model as fit in these studies. For growth parameters, 


\section{Table 3}

Summary of estimates of life history parameters and other information in the data set for 6 taxonomic groups created through a literature review and used in this study. Data types include the asymptotic length $\left(L_{\infty}\right)$, growth coefficient $(K)$, oldest recorded age $\left(A_{\max }\right)$, ratio of maximum length $\left(L_{\max }\right)$ to $L_{\infty}$, ratio of natural mortality $(M)$ to $K$, ratio of the length at which $50 \%$ of individuals are mature $\left(L_{\text {mat }}\right)$ to the expected length at the oldest recorded age $\left(L_{\text {Amax }}\right)$, and ratio of $L_{\text {mat }}$ to $L_{\infty}$. For the family Labridae, species from small-bodied genera were not included; for the family Serranidae, the Anthias genus was not included; and, for the shark group, only families from the orders Carcharhiniformes and Lamniformes were included. Standard deviations are provided in parentheses for ratios. All length values are total lengths.

\begin{tabular}{|c|c|c|c|c|c|c|}
\hline Data type & $\begin{array}{l}\text { Haemulidae } \\
\text { (grunts) }\end{array}$ & $\begin{array}{l}\text { Holocentridae } \\
\text { (soldierfishes) }\end{array}$ & $\begin{array}{l}\text { Labridae } \\
\text { (wrasses) }\end{array}$ & $\begin{array}{c}\text { Serranidae } \\
\text { (groupers) }\end{array}$ & Sharks & $\begin{array}{c}\text { Siganidae } \\
\text { (rabbitfishes) }\end{array}$ \\
\hline No. of species considered & 134 & 86 & 334 & 264 & 287 & 29 \\
\hline No. of species with growth study & 14 & 2 & 12 & 58 & 23 & 6 \\
\hline No. of species with maturity study & 5 & 2 & 9 & 32 & 20 & 6 \\
\hline$L_{\infty}(\mathrm{mm})$ & $203-917$ & - & $133-981$ & $148-2006$ & $733-4218$ & - \\
\hline$K\left(\right.$ year $\left.^{-1}\right)$ & $0.19-1.00$ & - & $0.07-0.89$ & $0.06-1.39$ & $0.04-1.01$ & - \\
\hline$A_{\max }($ years $)$ & $5-36$ & - & $7-78$ & $4-76$ & $7-44$ & - \\
\hline$L_{\max }$ to $L_{\infty}$ & $1.02(0.11)$ & - & $1.12(0.13)$ & $1.10(0.14)$ & $0.95(0.11)$ & - \\
\hline$M$ to $K$ & $0.55(0.29)$ & - & $0.68(0.39)$ & $0.81(0.48)$ & $1.53(0.82)$ & - \\
\hline$L_{\text {mat }}$ to $L_{\text {Amax }}$ & $0.80(0.14)$ & - & $0.48(0.16)$ & $0.60(0.10)$ & $0.78(0.10)$ & - \\
\hline$L_{\text {mat }}$ to $L_{\infty}$ & $0.79(0.15)$ & - & $0.48(0.17)$ & $0.58(0.12)$ & $0.70(0.12)$ & - \\
\hline
\end{tabular}

we selected only estimates for males and females combined. As a result, we were able to combine estimates from these studies more easily with data from others in which sex was undifferentiated. Further, sexes are not differentiated in most size-composition data sets in data-limited situations, and growth curves that are not sex specific are typically needed to run simple length-based assessment models with such data sets. For maturity, we obtained $L_{\text {mat }}$ for females only, given that the reproductive potential of a stock is almost always tied to mature female biomass in population models. We converted all length values to total lengths in millimeters; total length was the length measurement used in this study and by Nadon and Ault (2016). Conversion factors obtained from FishBase were used to do so. In a limited number of cases in which multiple studies were available for a single species, we selected the most reliable source, on the basis of sample size and publication source.

For the parameter $A_{\max }$, the age of the oldest reported fish in a study was selected. If multiple longevity values were available for a certain species, we selected the oldest recorded age as the $A_{\max }$ value. Values of $M$ were obtained by using the approach presented in Hewitt and Hoenig (2005), under the assumption that $5 \%$ of a cohort is left at the oldest recorded age $(S=0.05$; see Equation 2). Note that this assumption was used to obtain $M$ estimates to fit model C (i.e., $M \sim K+L_{\max }$ ). In practice, when using the stepwise approach, we can convert the $M$ estimates output from the model back to $A_{\max }$ values and calculate a new $M$ estimate under a different set of assumptions (e.g., $S=0.01$; Pauly, 1980; Then et al., 2015). These options are available in the $R$ package that implements the stepwise approach (see the "Discussion" section).
Quality control was performed on the studies found during the literature review by using the same guidelines outlined in Nadon and Ault (2016). Requirements included discarding any growth studies that involved lengthfrequency analysis or back-calculations. We kept only studies based on the aging of fish through the use of hard parts, primarily otoliths, vertebrae, and dorsal spines for sharks (Natanson et al., 2018; Natanson and Deacy, 2019). Finally, any studies that occurred in waters with mean sea-surface temperatures (SST) below $20^{\circ} \mathrm{C}$ were removed from consideration because of the well-established negative correlation between longevity and water temperature (Pauly, 1980; Jobling, 1994; Choat and Robertson, 2002). Exclusion of studies from regions with low temperatures was a sensible choice given that many of the families examined in our study are typically found in tropical waters where temperatures are usually well above the threshold of $20^{\circ} \mathrm{C}$. Given that the ranges of our taxonomic groups center on tropical areas, only 3 species were excluded because of temperature criteria ( 1 wrasse and 2 groupers). The models also excluded genera that were clear outliers in certain families.

After obtaining the new data set of life history traits and putting it through quality control, we visually explored the shape of the functional relationships between paired parameters $\left(L_{\max } \sim L_{\infty}, K \sim L_{\infty}, M \sim K\right.$, and $\left.L_{\text {mat }} \sim L_{\text {Amax }}\right)$ by plotting data points in scatter plots for each new taxon (by new, we mean taxa added to those already included in the work of Nadon and Ault, 2016). We then tested the fit of linear, power, and exponential functions to these data points and obtained the maximum likelihood estimates for all parameters of models A-D by using the mle2 function of the package bbmle (vers. 1.0.19; Bolker, 2008; Fox, 2008) in the $\mathrm{R}$ statistical computing and programming environment (vers. 3.4.0; R Core Team, 2017). 


\section{Testing the expansion of the stepwise approach}

To test our expansion of the approach of Nadon and Ault (2016), we compared the probability distributions of the values of life history parameters obtained through use of the stepwise approach with the probability distributions from published growth and maturity studies on a species in each of the new taxonomic groups. We selected these species on the basis of the availability of published values of life history parameters from indepth studies and the availability of an independent estimate of $L_{\max }$ that we obtained from visual census data collected during NOAA diver surveys. We selected the blacktip reef shark (Carcharhinus melanopterus) (Chin et al., 2013), the camouflage grouper (Epinephelus polyphekadion) (Rhodes et al., 2011), the javelin grunter (Pomadasys kaakan) (Al-Husaini et al., 2002), and the redbreasted wrasse (Cheilinus fasciatus) (Hubble, 2003). The NOAA diver surveys are conducted every 3 years around approximately 50 islands and atolls in the central Pacific Ocean (the main and Northwestern Hawaiian Islands, American Samoa, and the Mariana Archipelago). For these surveys, a stratified random sampling design is used to select locations around the islands at which to count fish by using a stationarypoint-count approach (Ayotte et al. ${ }^{1}$ ). During surveys, divers also record approximate total lengths of sighted fish to the nearest centimeter; divers are consistently trained in this exercise.

Next, we compared the precision and accuracy of the estimates of life history parameters from use of the stepwise procedure for the 4 new taxa included in this study. We used the same criteria as Nadon and Ault (2016) to evaluate the precision and accuracy of estimates made with the stepwise approach. We compared the widths of distributions of standard deviations (precision) and the distances between medians (accuracy) from the stepwise analysis with those from aging and maturity studies. We ran the stepwise simulation for these species, starting with local $L_{\max }$ values obtained from a data set of lengths of blacktip reef sharks, redbreasted wrasse, and camouflage grouper from NOAA diver surveys. We did not have an independent data set of lengths of javelin grunter; therefore, we used the 99th percentile of the lengths in the original growth study (Al-Husaini et al., 2002) as the $L_{\max }$ value for this species.

Finally, we evaluated the performance of the stepwise approach when determining a simple stock status metric, the spawning potential ratio (SPR) (Goodyear, 1990), by measuring its precision and accuracy as we did for the life history parameters. Spawning potential ratio is the ratio of spawning stock biomass (SSB) per recruit under

\footnotetext{
${ }^{1}$ Ayotte, P., K. McCoy, A. Heenan, I. Williams, and J. Zamzow. 2015. Coral reef ecosystem program standard operating procedures: data collection for rapid ecological assessment fish surveys. NOAA, Natl. Mar. Fish. Serv., Pac. Isl. Fish. Sci. Cent. Admin. Rep. H-15-07, 33 p. [Available from website.]
}

a certain fishing mortality rate $(F)$ divided by the same metric when fishing is absent:

$$
S S B=\sum_{A_{\text {mat }}}^{A_{\max }} \bar{N}_{\mathrm{a}} \bar{W}_{\mathrm{a}},
$$

where $A_{\text {mat }}=$ the age at maturity (derived directly from $L_{\text {mat }}$ ), until $A_{\text {max }}$; $\overline{\mathrm{N}}_{\mathrm{a}}=$ the number of individuals; and

$\overline{\mathrm{W}}_{\mathrm{a}}$ = the expected individual weight (derived from a length-weight relationship; see Equation 10) in each age class $a$, beginning from $A_{\text {mat }}$.

The number of individuals in an age class is obtained by using the following exponential mortality equation:

$$
\bar{N}_{\mathrm{a}+\Delta \mathrm{a}}=\bar{N}_{\mathrm{a}} e^{-\left(S_{\mathrm{a}} F+\mathrm{M}\right) \Delta \mathrm{a}},
$$

where $S_{\mathrm{a}}=$ the knife-edge selectivity at age $a$ (set to age 2 for all species, to simplify comparisons).

Given that the SPR is a per-recruit metric, the number of fish at age 0 is simply set to 1 (i.e., $N_{\mathrm{a}=0}=1$ ). Values for parameters of the dependent relationship of weight $(W)$ to length (L) ( $\alpha$ and $\beta$, where $\left.W=\alpha \times L^{\beta}\right)$, necessary for SPR calculations, were obtained from FishBase. Using the above equations, we calculated SPR values for all 4 test species at different fishing rates ranging from 0 to $F>4 M$ from values of both the life history studies and stepwise approach. We then compared the SPR probability distributions of the test species in a fashion similar to that used for life history parameters. We calculated the SPR at different $F$ values given the curvilinear relationship between the SPR and $F$.

Finally, we compared the stepwise parameter estimates to those from use of the alternative meta-analytical approach FishLife (Thorson et al., 2017). The FishLife approach fits a multivariate model with a taxonomic structure to generate probability distributions of life history parameters at different taxonomic levels (species, genus, family, order, and class). Using the $\mathrm{R}$ package FishLife (Thorson, 2017), we generated probability distributions for our 4 test species at the genus and family levels. We plotted these distributions with the results from use of the stepwise approach as well as with the published parameter estimates to evaluate their accuracy. All analyses were conducted in $\mathrm{R}$.

\section{Results}

\section{Life history parameter models for new taxa}

The parameter $L_{\max }$ had a close relationship with $L_{\infty}$ for all 4 taxonomic groups (Fig. 2). All 4 relationships were best explained by a linear function with a relatively narrow normal error distribution. The standard deviation for sharks was much larger than for the other 3 groups (Table 2), an outcome that was expected given their larger size ranges. Larger (>1000 mm total length) grouper species had higher variability associated with $L_{\infty}$ estimates in comparison to smaller species; therefore, for analysis of the $L_{\infty} \sim L_{\max }$ 

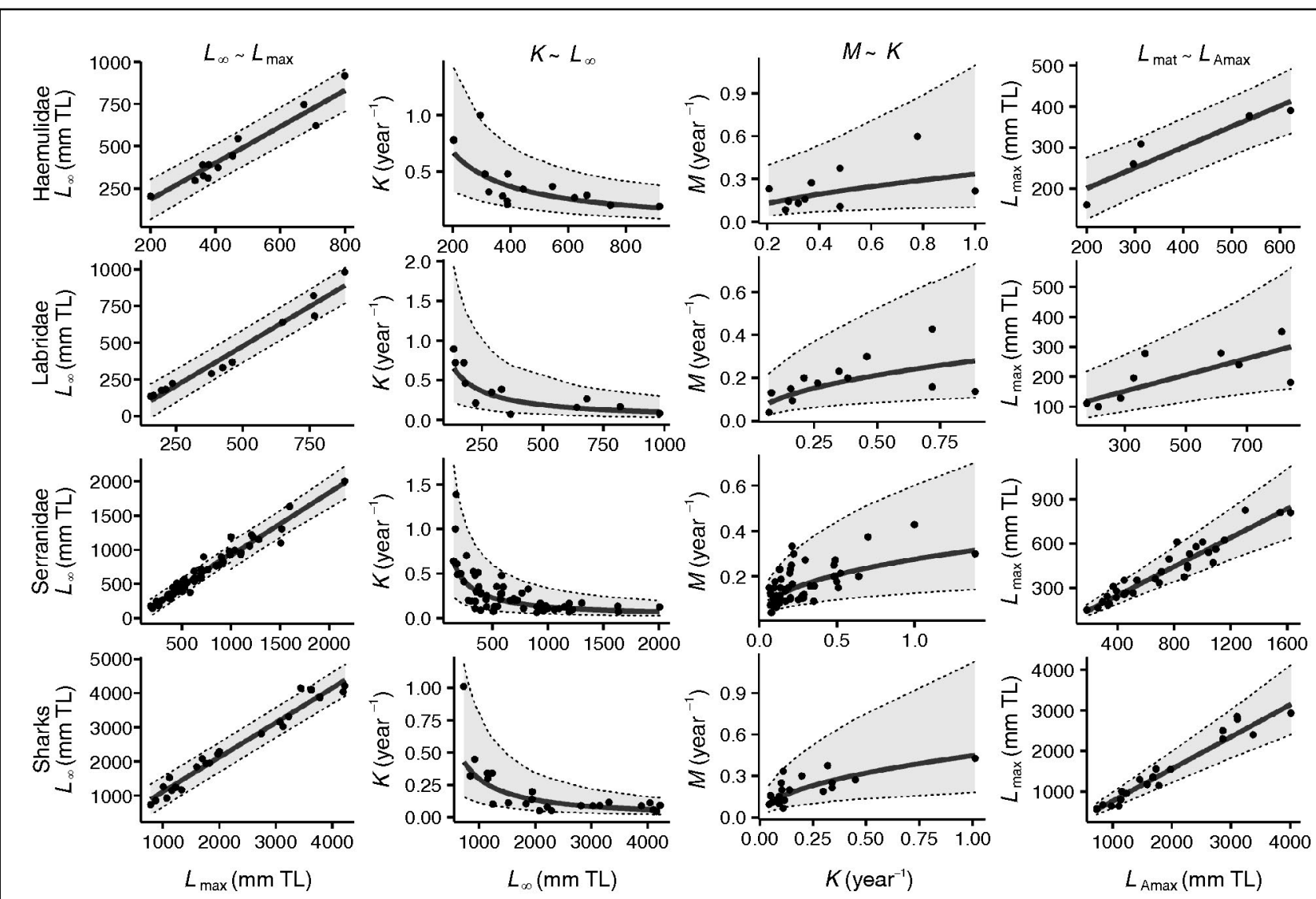

Figure 2

Modeled statistical relationships between life history parameters, the asymptotic length $\left(L_{\infty}\right)$, maximum length $\left(L_{\max }\right)$, growth coefficient $(K)$, natural maturity $(M)$, and expected length at the oldest recorded age $\left(L_{\text {Amax }}\right)$, in 4 pairs for grunts (Haemulidae), wrasses (Labridae), groupers (Serranidae), and sharks from the orders Carcharhiniformes and Lamniformes. Black circles indicate the estimates of life history parameters obtained from studies. The solid dark gray lines are the lines of best fit, produced by using a linear or power model. Gray areas indicate the $95 \%$ confidence intervals of the lines of best fit. Note that model C (see Figure 1) also includes the $L_{\max }$ parameter for most families, but only the 1-variable $M \sim K$ relationships are presented here. $\mathrm{TL}=$ total length.

relationship, we divided the grouper species into 2 size ranges by using an $L_{\max }$ break point of $1000 \mathrm{~mm}$ total length. The growth parameter $K$ had a negative curvilinear relationship with the $L_{\infty}$ parameter (Fig. 2). A power function best matched this relationship, and a lognormal error distribution was used to account for the decrease in variability that occurred as $L_{\infty}$ values increased. A power function with a lognormal error distribution was also used to model $M$ as a function of $K$ and $L_{\max }$ (Fig. 2). Most of the available $M$ and $K$ data points were toward the lower end of the ranges of these parameters with only a few available data points at high values. It is likely that these limited data points had an outsized influence on the model fit. A positive, curvilinear relationship between $M$ and $K$ indicates slower growing fish have lower $M$, as was expected.

A linear model was used for all 4 relationships between $L_{\text {mat }}$ and $L_{\text {Amax }}$ (Fig. 2). Parameters for sharks, wrasses, and groupers were modeled with a lognormal error distribution because variability increased with larger $L_{\text {Amax }}$ values, and parameters for grunts followed a normal error distribution. Maturity data were available for only 5 species of grunts, and the relationship would likely benefit from a larger sample size. As previously reported by Nadon and Ault (2016), $L_{\text {Amax }}$ was a better predictor of $L_{\text {mat }}$ than $L_{\infty}$, as indicated by the higher coefficients of determination $\left(r^{2}\right)$ for results from the $L_{\text {mat }} \sim L_{\text {Amax }}$ models (Table 4 ).

\section{Comparing distributions: stepwise approach, life history studies, and FishLife}

For the 4 test species, we compared the probability distributions for key life history parameters generated by using the stepwise approach with those found in species-specific life history studies (Fig. 3). Like the results of the tests used by Nadon and Ault (2016), the estimates of life history parameters resulting from use of the stepwise approach had greater standard deviations than those from actual studies. The estimates from the stepwise simulation 


\section{Table 4}

Overall coefficients of determination for the linear models of the relationships of the length at which $50 \%$ of individuals are mature $\left(L_{\text {mat }}\right)$ as a dependent variable to either expected length at infinite age $\left(L_{\infty}\right)$ or to expected length at the oldest recorded age $\left(L_{\text {Amax }}\right)$ for 3 families of tropical coastal fish species and for sharks from the orders Carcharhiniformes and Lamniformes.

\begin{tabular}{lcc}
\hline Taxon & $L_{\text {mat }} \sim L_{\infty}$ & $L_{\text {mat }} \sim L_{\text {Amax }}$ \\
\hline Haemulidae (grunts) & 0.82 & 0.86 \\
Labridae (wrasses) & 0.36 & 0.46 \\
Serranidae (groupers) & 0.86 & 0.90 \\
Sharks & 0.91 & 0.95 \\
All families & 0.74 & 0.79
\end{tabular}

were reasonably accurate (i.e., useful for management purposes), generating median values within $25 \%$ of the estimates from life history studies for 14 of the 16 combinations of parameters and species (Table 5). Across all 4 test species, the stepwise predictions for $M$ appear to be the most accurate. The blacktip reef shark was the test species with the most accurate results from the stepwise approach for all 4 parameters. The stepwise approach performed moderately well for the grunts on the basis of our test species javelin grunter. Despite high levels of variability, the stepwise approach appeared to be accurate for camouflage grouper, especially for $L_{\infty}, K$, and $M$. The $L_{\text {mat }}$ value was estimated at $352 \mathrm{~mm}$ in the test life history study and at $284 \mathrm{~mm}$ by using the stepwise approach, a result that can be explained by this species being an outlier with its $L_{\text {mat }}$ close to $80 \%$ of its $L_{\infty}$ (as opposed to $60 \%$ of the $L_{\infty}$ for groupers, on average).
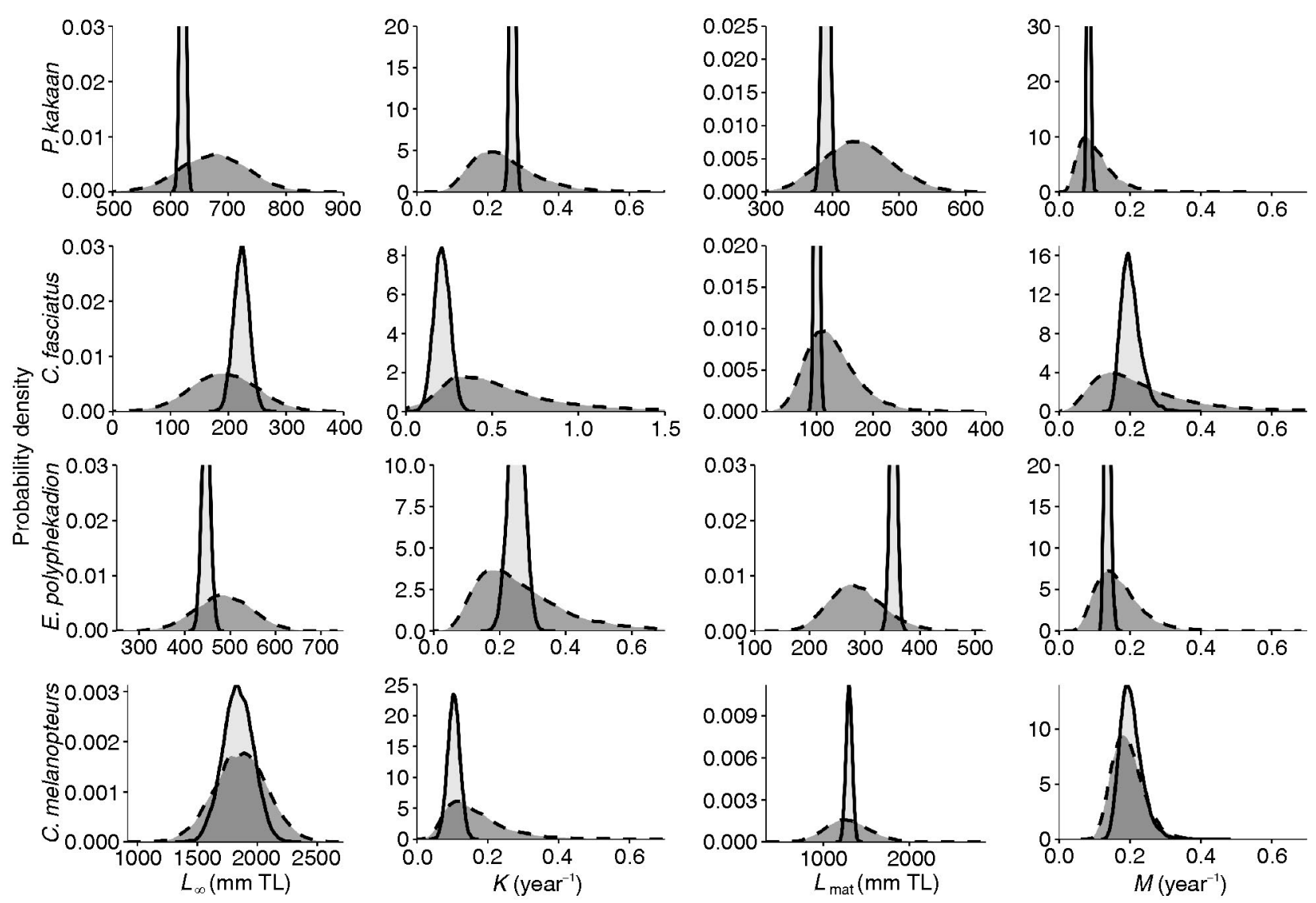

Figure 3

Probability distributions of estimates of life history parameters from life history studies (light gray areas and solid lines) and from use of the stepwise stochastic simulation approach (dark gray areas and dashed lines) for the 4 selected test species: javelin grunter (Pomadasys kaakan), redbreasted wrasse (Cheilinus fasciatus), camouflage grouper (Epinephelus polyphekadion), and blacktip reef shark (Carcharhinidae melanopterus). The parameters include the asymptotic length $\left(L_{\infty}\right)$, growth coefficient $(K)$, length at which $50 \%$ of individuals are mature $\left(L_{\text {mat }}\right)$, and natural mortality $(M)$. TL=total length. 


\section{Table 5}

Comparison of descriptive statistics of the probability distributions of life history parameters obtained from published life history studies to those from the use of the stepwise stochastic simulation approach for the 4 selected test species: javelin grunter (Pomadasys kaakan), redbreasted wrasse (Cheilinus fasciatus), camouflage grouper (Epinephelus polyphekadion), and blacktip reef shark (Carcharhinidae melanopterus). The life history and other model parameters include the maximum length $\left(L_{\max }\right)$, asymptotic length $\left(L_{\infty}\right)$, growth coefficient $(K)$, length at which $50 \%$ of individuals are mature $\left(L_{\text {mat }}\right)$, natural mortality $(M)$, spawning potential ratio (SPR) at which fishing mortality $(F)$ was equal to $M$, and SPR at which $F$ was equal to 2 times $M$. The median, standard deviation (SD), ratio of the SD from stepwise simulation to the SD from life history studies (SD ratio), and the standardized distance between the stepwise medians and medians from life history studies (relative error $[\mathrm{RE}]$ ) are presented for each parameter, except $L_{\max }$, which was a measured value in the study. The median $L_{\max }$ values used to obtain probability distributions for the 4 test species are provided. TL=total length.

\begin{tabular}{|c|c|c|c|c|c|c|c|c|}
\hline \multirow[b]{2}{*}{ Parameter } & \multicolumn{2}{|c|}{ P. kaakan } & \multicolumn{2}{|c|}{ C. fasciatus } & \multicolumn{2}{|c|}{ E. polyphekadion } & \multicolumn{2}{|c|}{ C. melanopterus } \\
\hline & Study & Stepwise & Study & Stepwise & Study & Stepwise & Study & Stepwise \\
\hline $\begin{array}{l}L_{\max }(\mathrm{mm} \mathrm{TL}) \\
L_{\infty}(\mathrm{mm} \mathrm{TL})\end{array}$ & - & 655 & - & 236 & - & 520 & - & 1737 \\
\hline Median & 621 & 675 & 223 & 192 & 447 & 487 & 1840 & 1862 \\
\hline $\mathrm{SD}$ & 5 & 58 & 13 & 57 & 9 & 62 & 127 & 225 \\
\hline $\mathrm{SD}$ ratio & - & 12 & - & 4 & - & 7 & - & 2 \\
\hline RE (\%) & - & 9 & - & -14 & - & 9 & - & 1 \\
\hline \multicolumn{9}{|l|}{$K\left(\right.$ year $\left.^{-1}\right)$} \\
\hline Median & 0.27 & 0.24 & 0.21 & 0.47 & 0.25 & 0.24 & 0.10 & 0.15 \\
\hline $\mathrm{SD}$ & 0.01 & 0.09 & 0.05 & 0.35 & 0.02 & 0.14 & 0.02 & 0.09 \\
\hline $\mathrm{SD}$ ratio & - & 13 & - & 7 & - & 8 & - & 5 \\
\hline $\mathrm{RE}(\%)$ & - & -11 & - & 124 & - & -4 & - & 50 \\
\hline \multicolumn{9}{|l|}{$L_{\text {mat }}(\mathrm{mm} \mathrm{TL})$} \\
\hline Median & 390 & 435 & 100 & 121 & 352 & 284 & 1300 & 1267 \\
\hline SD & 5 & 52 & 4 & 45 & 6 & 50 & 35 & 260 \\
\hline $\mathrm{SD}$ ratio & - & 10 & - & 11 & - & 8 & - & 7 \\
\hline RE (\%) & - & 12 & - & 21 & - & -19 & - & -3 \\
\hline \multicolumn{9}{|l|}{$M\left(\right.$ year $\left.^{-1}\right)$} \\
\hline Median & 0.08 & 0.10 & 0.20 & 0.20 & 0.14 & 0.16 & 0.21 & 0.19 \\
\hline $\mathrm{SD}$ & 0.004 & 0.05 & 0.02 & 0.16 & 0.01 & 0.07 & 0.03 & 0.05 \\
\hline $\mathrm{SD}$ ratio & - & 13 & - & 8 & - & 7 & - & 2 \\
\hline $\mathrm{RE}(\%)$ & - & 25 & - & 0 & - & 14 & - & -5 \\
\hline \multicolumn{9}{|l|}{$\mathrm{SPR} F=\mathrm{M}$} \\
\hline Median & 0.38 & 0.39 & 0.22 & 0.29 & 0.27 & 0.35 & 0.09 & 0.12 \\
\hline $\mathrm{SD}$ & 0.01 & 0.09 & 0.04 & 0.15 & 0.02 & 0.11 & 0.02 & 0.08 \\
\hline $\mathrm{SD}$ ratio & - & 9 & - & 4 & - & 6 & - & 4 \\
\hline $\mathrm{RE}(\%)$ & - & 3 & - & 32 & - & 30 & - & 33 \\
\hline \multicolumn{9}{|l|}{$\mathrm{SPR} F=2 \mathrm{M}$} \\
\hline Median & 0.18 & 0.18 & 0.08 & 0.13 & 0.11 & 0.18 & 0.011 & 0.023 \\
\hline SD & 0.01 & 0.07 & 0.02 & 0.11 & 0.01 & 0.08 & 0.005 & 0.033 \\
\hline $\mathrm{SD}$ ratio & - & 7 & - & 6 & - & 8 & - & 7 \\
\hline $\mathrm{RE}(\%)$ & - & 0 & - & 63 & - & 64 & - & 109 \\
\hline
\end{tabular}

To test the influence of the estimates of life history parameters from use of the stepwise approach on stock status, we used stepwise parameter predictions to calculate SPR distributions at $F$ values ranging from 0 to more than 4 times $M$. The use of the stepwise approach and life history studies generated relatively similar median SPR values across the range of $F$, but the stepwisederived SPR values were more variable, as expected, because of higher variability in life history parameters (Fig. 4). Higher variability was especially true for the redbreasted wrasse, given the low number of studies that were available for the wrasse family and the resulting higher uncertainty in parameter estimates from stepwise simulation. Averaged across all 4 test species, the absolute distance between the stepwise-derived SPR values and those from life history studies was 0.05 when $F$ was equal to $M$ and was 0.03 when $F$ was equal to 2 times $M$. It is worth noting that, for 3 of the 4 test species, the SPR curve for estimates from use of the stepwise approach was higher than that for study values, but it is unclear if this bias is an implicit one, given the small number of species included in tests. 


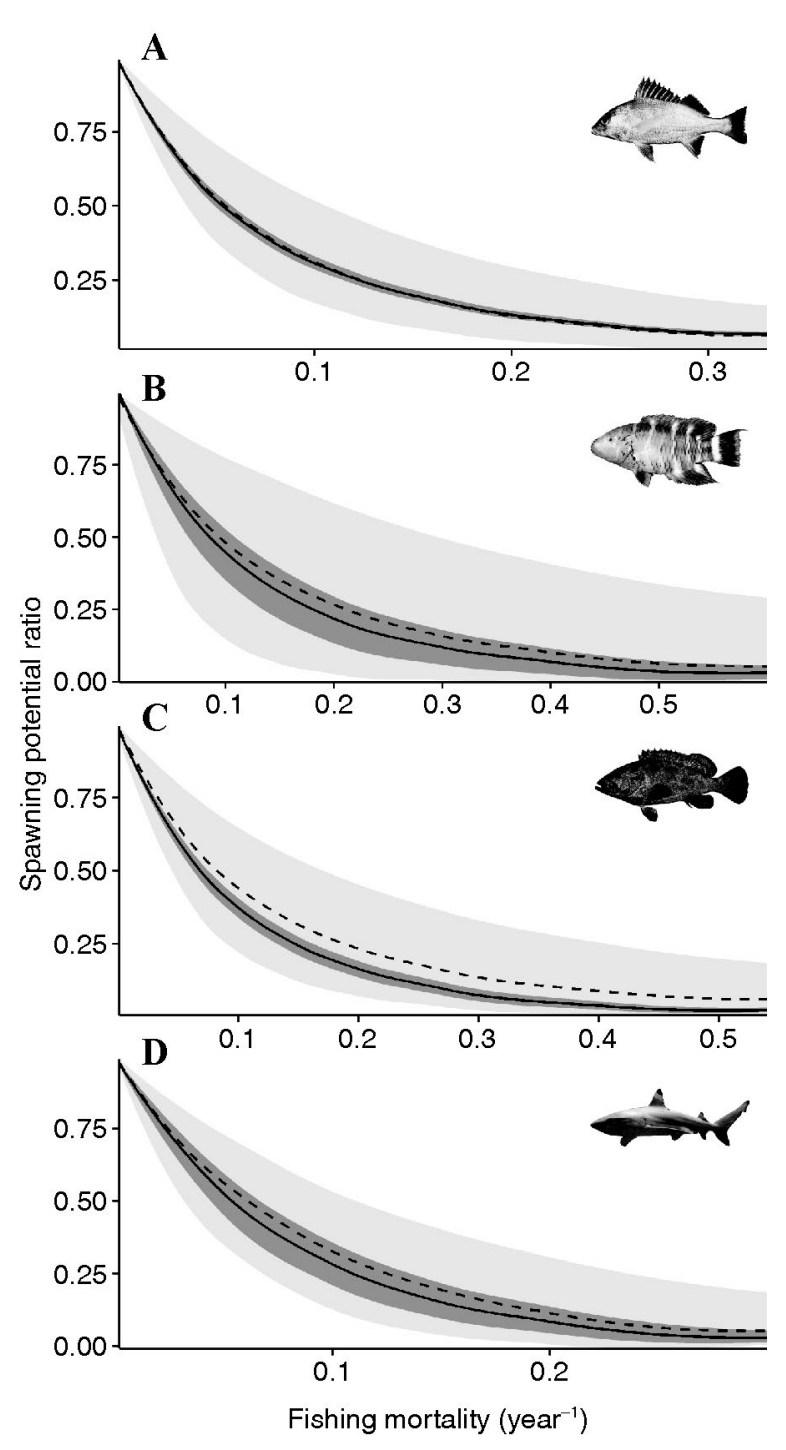

Figure 4

The spawning potential ratios at various fishing mortality rates derived by using parameter estimates from life history studies (dark gray areas and solid lines) and from use of the stepwise stochastic simulation approach (light gray areas and dashed lines) for the 4 selected test species: (A) javelin grunter (Pomadasys kaakan), (B) redbreasted wrasse (Cheilinus fasciatus), (C) camouflage grouper (Epinephelus polyphekadion), and (D) blacktip reef shark (Carcharhinidae melanopterus). Lines represent median values, and shaded areas represent $95 \%$ confidence intervals. Fishing mortality rates ranged from 0 to more than 4 times natural mortality.

Lastly, we compared the stepwise approach with the FishLife meta-analytical approach (Thorson et al., 2017). On average, the stepwise approach was more accurate than the FishLife approach implemented at both the genus and family levels for all parameters except $K$ (Table 6, Figs. 5 and 6 ). The accuracy of the ratios of $L_{\text {mat }}$ to $L_{\infty}$ was only slightly better for the stepwise approach. However, the accuracy of $L_{\infty}, M, L_{\text {mat }}$, and the ratio of $M$ to $K$ was significantly higher for the stepwise approach. For example, the $L_{\text {mat }}$ medians from stepwise simulation were on average $11 \%$ removed from the study values, and the $L_{\text {mat }}$ average median values from the FishLife approach where more than $30 \%$ removed from those in published studies. In terms of precision, the stepwise approach was more precise for $L_{\infty}, M$, and $L_{\text {mat }}$. The FishLife distributions were slightly more precise for the ratios of $L_{\text {mat }}$ to $L_{\infty}$ and of $M$ to $K$ and more precise for the $K$ parameter (standard deviations of 0.12 versus 0.17 ).

\section{Discussion}

Through this study, we have successfully extended the stepwise stochastic simulation approach to grouper, wrasse, grunt, and shark taxa. Our findings indicate that the stepwise approach could be further extended to fit specific management and scientific needs for additional families by replicating the effort in this study. The new models for these 4 taxa can now be used to calculate values for key life history parameters in data-poor situations and to implement stock assessment models (Nadon, 2017, 2019). The model in which the stepwise approach is applied now includes 10 taxonomic groups and is available as the $R$ package StepwiseLH on the GitHub website.

\section{Caveats}

The stepwise approach, as well as other similar metaanalytical approaches, carries a lot of uncertainty into estimates of life history parameters and is not meant to replace proper life history studies. These approaches are meant to be temporary solutions to alleviate the pressing needs for assessment and management of data-poor fish populations. Although we tried to limit the sources of variability in our data set as much as possible, we had to make several compromises to retain a sufficient number of data points. For example, although most of the speciesspecific values of $L_{\max }, L_{\infty}, K$, and $A_{\max }$ used to create our data set are from single studies (and therefore single locations), maturity studies were often conducted separately and $L_{\text {mat }}$ values can therefore be from a location different from the area where values of other parameters are from for many species. Specifically, 2 of the 5 maturity studies for grunts and 12 of the 32 maturity studies for groupers were not conducted at the same location as their corresponding growth studies (although only 2 of 20 shark maturity studies and none of the wrasse studies were conducted in different locations from those of their growth studies). This compromise may have added more variability to our $L_{\text {mat }}$ estimates but likely did not introduce any specific biases.

Additionally, the lack of data points and different model fitting procedures for juveniles can have an effect on the $L_{\infty}$ and $K$ parameter estimates. We tried controlling for 


\section{Table 6}

Comparison of the accuracy and precision of estimates of life history parameters between use of the stepwise stochastic simulation approach and use of the FishLife approach. The reported values are the average results for all 4 of the selected test species. The FishLife model generated probability distributions at the genus and family levels. The parameters include the asymptotic length $\left(L_{\infty}\right)$, growth coefficient $(K)$, natural mortality $(M)$, length at which $50 \%$ of individuals are mature $\left(L_{\text {mat }}\right)$, and the ratios of $L_{\text {mat }}$ to $L_{\infty}$ and of $M$ to $K$. The accuracy metric is the standardized distance from the median values generated with the meta-analytical approaches to values from life history studies (in percentage units). Precision is reported as the standard deviation of each parameter (in millimeters for total lengths and on an annual basis for $M$ and $K$ ). An asterisk (*) indicates that results are the most accurate or precise for that life history parameter among the approaches tested.

\begin{tabular}{lclllll}
\hline Modeling approach & $L_{\infty}$ & $K$ & $M$ & $L_{\text {mat }}$ & $L_{\text {mat }}$ to $L_{\infty}$ & $M$ to $K$ \\
\hline $\begin{array}{l}\text { Accuracy } \\
\quad \text { Stepwise }\end{array}$ & $8^{*}$ & 45 & $11^{*}$ & $11^{*}$ & $17^{*}$ & $36^{*}$ \\
$\quad$ FishLife (genus) & 58 & $30^{*}$ & 99 & 50 & 19 & 87 \\
$\quad$ FishLife (family) & 17 & 45 & 86 & 30 & 18 & 78 \\
$\begin{array}{l}\text { Precision } \\
\text { Stepwise }\end{array}$ & $111^{*}$ & 0.17 & $0.08^{*}$ & $107^{*}$ & 0.13 & 0.46 \\
$\quad$ FishLife (genus) & 449 & $0.12^{*}$ & 0.14 & 248 & $0.08^{*}$ & $0.38^{*}$ \\
$\quad$ FishLife (family) & 611 & 0.21 & 0.22 & 340 & 0.10 & 0.42
\end{tabular}
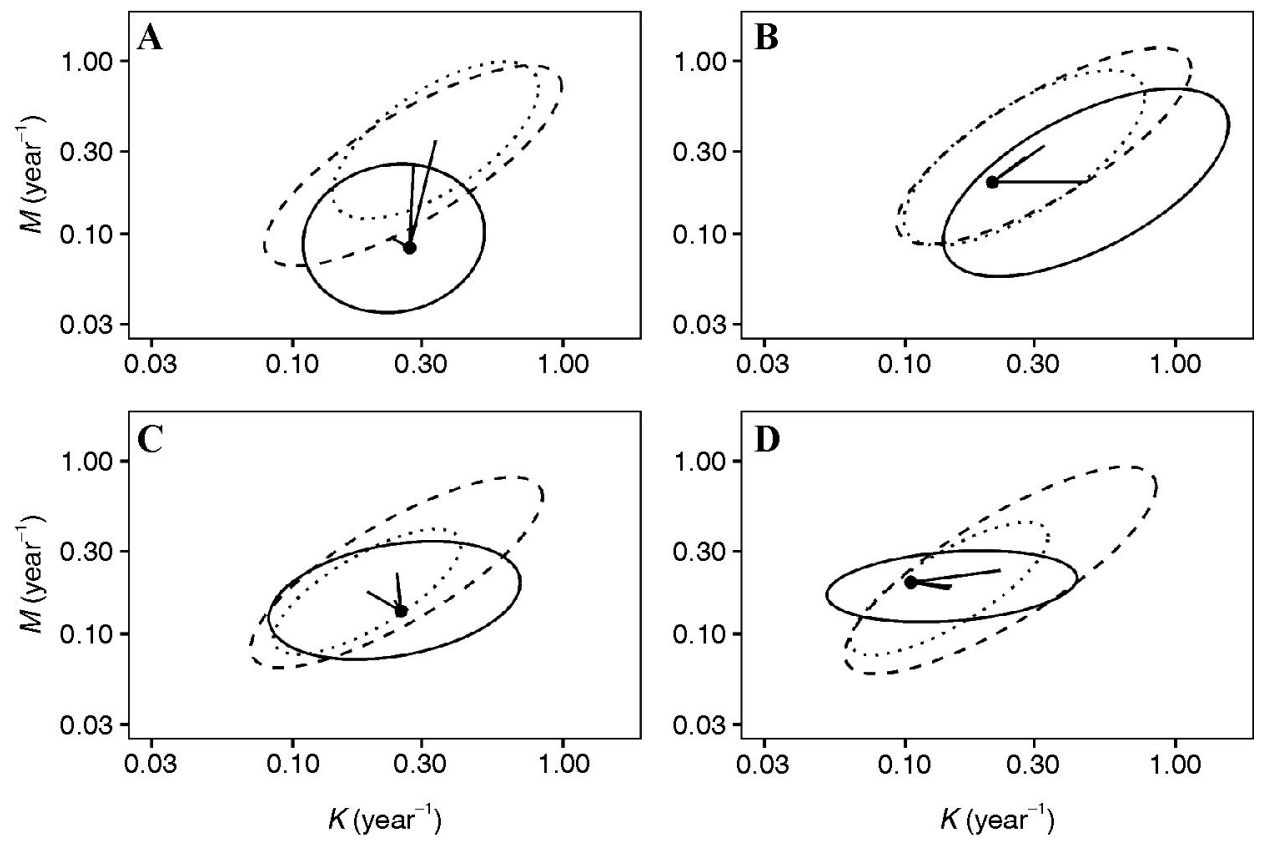

Figure 5

The 95\% confidence intervals for probability distributions of natural mortality $(M)$ and the growth coefficient $(K)$ from use of the stepwise stochastic simulation approach (solid circular lines) and from use of the FishLife approach at both the genus (dotted circular lines) and family (dashed circular lines) levels for the 4 selected test species: (A) javelin grunter (Pomadasys kaakan), (B) redbreasted wrasse (Cheilinus fasciatus), (C) camouflage grouper (Epinephelus polyphekadion), and (D) blacktip reef shark (Carcharhinidae melanopterus). Published values from life history studies (black circles) are also presented for each species, with line segments connecting the median of the distributions to the study value. 

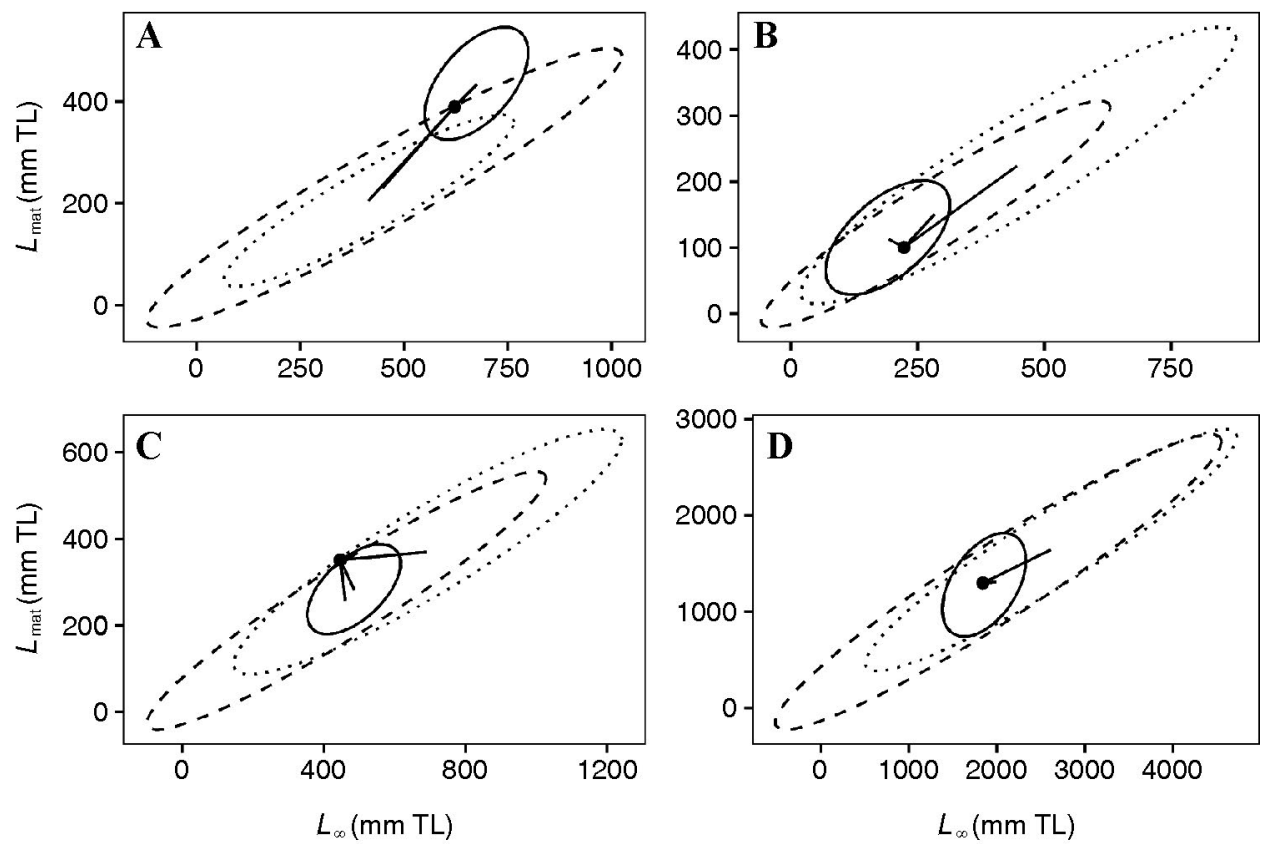

Figure 6

The 95\% confidence intervals for probability distributions of the asymptotic length $\left(L_{\infty}\right)$ and length at which $50 \%$ of individuals are mature $\left(L_{\text {mat }}\right)$ from use of the stepwise stochastic simulation approach (solid circular lines) and from use of the FishLife approach at both the genus (dotted circular lines) and family (dashed circular lines) levels for the 4 selected test species: (A) javelin grunter (Pomadasys kaakan), (B) redbreasted wrasse (Cheilinus fasciatus), (C) camouflage grouper (Epinephelus polyphekadion), and (D) blacktip reef shark (Carcharhinidae melanopterus). Published values from life history studies (black circles) are also presented for each species, with line segments connecting the median of the distributions to the study value. TL=total length.

this issue by removing growth studies with highly negative $A_{0}$ from the analysis (an indication of a lack of data points for juveniles needed to anchor the growth curve near the origin). Again, we believe removing studies with highly negative $A_{0}$ simply adds to the overall variability and does not introduce any specific bias.

Another caveat is that we used the SST at the locations of the life history studies, and those temperatures may not reflect the lifelong SST exposure of highly migratory species. In the study described here, the difference in temperatures is mainly a concern for certain shark species that may migrate between tropical and temperate waters. Therefore, our SST limit of $20^{\circ} \mathrm{C}$ may not exclude species that spend most of their time in $\mathrm{SST}<20^{\circ} \mathrm{C}$ if the study took place in a warmer climate. A difference in temperature may introduce a slight bias in $M$ estimates, but it is unlikely that the tropical or temperate species that occur in $\mathrm{SST}$ above $20^{\circ} \mathrm{C}$ spend much time in very cold SST.

Further, we used the $L_{\max }$ value from NOAA diver surveys to distance our test from the $L_{\max }$ values in the original data set and to reduce the potential for confounding test results. The only input needed for the stepwise approach is $L_{\max }$, and we wanted this value to come from an independent source. We could have used $L_{\max }$ from the original life history study, as we did for the javelin grunter, but we felt this was a more independent test.

Finally, it would have been more appropriate to test our stepwise approach on species not included in the regression models we used to build our approach. However, we did not want to exclude the data from our 4 test species in these regression models given our low sample sizes. It is important to note that parameter estimates for the 4 test species came from the same database (FishBase) as those used in the FishLife multivariate models; therefore, their inclusion does not bias our approach comparisons in favor of the stepwise approach.

\section{Sources of variability in estimates of life history parameters}

There are multiple sources of variability included in the distributions of life history parameters from the stepwise simulation. Some sources are directly modeled, others are likely indirectly included as part of the overall residual error of each model, and some minor sources of uncertainty were not included. The main source of 
variability is interspecific genetic differences that are a result of natural selection. This source of variability was modeled explicitly by using parameter estimates for individual species as data points in our regression models. A certain amount of intraspecific geographical variability in both genetics and habitat conditions also contributes to variability in estimates of life history parameters. Consequently, there may be some concern that we pooled data from across the world and therefore ignored geographical differences within species. Unfortunately, given that published data for most species came from only one location, it was impossible for us to directly control for geographical heterogeneity in life history parameters. Geographical differences in values of life history parameters for species simply add to the overall variability of the stepwise parameter estimates and should not cause any specific bias.

Another source of variability that was directly modeled are regression model coefficients. Coefficient variability was included by randomly sampling the multivariate normal distribution, as defined by the variancecovariance matrix. Similarly, uncertainty in the starting $L_{\max }$ parameter was directly included by sampling from a distribution or by bootstrapping raw $L_{\max }$ observations. Furthermore, the lack of access to raw age-at-length and length-at-maturity data, coupled with the fact that most published reports from life history studies do not include a parameter variance-covariance matrix, prevented us from directly including uncertainty from fitted values (i.e., $L_{\infty}, K$, and $L_{\text {mat }}$ ) in our models. This source of uncertainty, although not modeled explicitly, likely adds to the global residual error.

Finally, a few minor sources of uncertainty were not directly included because they are unlikely to have a major effect on output variability. Specifically, variability in $A_{0}$ is hard to measure given the sensitivity of this parameter to juvenile age-at-length data points. In our approach, we simply fixed this parameter to the overall mean of -0.6 . Further, we did not include uncertainty in the relationships of fork or standard length to total length that we used to convert all parameter data to total lengths. Not including uncertainty from length conversions is unlikely to be a major source of error, and the studies that publish these conversion factors rarely provide their associated variability. Finally, we did not specifically include variability in the $M$ estimates derived from $A_{\max }$ (Equation 8). The relationship between $M$ and longevity depends on the assumption of $S$. We fixed $S$ at 0.05 to convert our raw observations of $A_{\max }$ to $M$ in order to model the $M \sim K$ relationship. This assumption can be relaxed in the $\mathrm{R}$ package StepwiseLH by specifying an $S$ value and generating $M$ estimates under this new value. Uncertainty in the values of the $S$ parameter could be included by researchers as a separate step by using Monte Carlo simulations on this parameter.

Despite the various sources of uncertainty described in this section, it is important to note that use of the stepwise approach still results in reasonably accurate parameter estimates, as demonstrated in our tests.

\section{Parameter estimation}

In addition to producing results from the 4 models that relate key life history traits, we calculated the following ratios: $L_{\max }$ to $L_{\infty}, L_{\text {mat }}$ to $L_{\mathrm{Amax}}, L_{\text {mat }}$ to $L_{\infty}$, and $M$ to $K$, all Beverton-Holt invariants. Results from comparison of these ratios from our study with those previously published indicate that the invariants differ among taxonomic groups in our study (groupers, grunts, wrasses, and lamniform and carcharhiniform sharks). Our findings are consistent with previous investigations of life history invariants that found similar variance in relationships of life history traits between taxonomic groups of fish (Charnov and Berrigan, 1991; Nadon and Ault, 2016; Thorson et al., 2017).

The ratio of $M$ to $K$ is of particular interest because the relationship between $M$ and $K$ determines the overall shape of a growth trajectory (Hordyk et al., 2015). In our study, we used the criteria from Prince et al. (2015) to define a ratio of $M$ to $K$ that was $>1.0$ as indeterminate growth and a ratio of $M$ to $K$ that was $<1.0$ as determinate growth. Species with determinate growth are limited to a maximum size after which growth mostly ceases (Lincoln et al., 1982), and species with indeterminate growth are not limited to a maximum size but typically see growth slow with size (Sebens, 1987). Sharks were the only group with a ratio of $M$ to $K$ that was $>1.0$ (1.53), indicating indeterminate growth. This observation for sharks is consistent with the findings of indeterminate growth in the literature (Pardo et al., 2013; Heupel et al., 2014). All other families in the study described here had determinate growth patterns with ratios of $M$ to $K<1.0$.

On average, species with indeterminate growth will reach only a fraction of $L_{\infty}$ at $A_{\max }$, with an increasingly smaller proportion at higher ratios (Hordyk et al., 2015). Consequently, the ratio of $M$ to $K$ has a strong effect on the divergence between the parameters $L_{\infty}$ and $L_{\text {Amax }}$. As this ratio increases, the curvilinearity of the growth trajectory decreases and $L_{\infty}$ can increase drastically and become more of a fitting parameter than one related to $L_{\text {Amax }}$. An increase in the ratio of $M$ to $K$ ultimately reduces the ratio of $L_{\text {mat }}$ to $L_{\infty}$, while the ratio of $L_{\text {mat }}$ to $L_{\text {Amax }}$ stays similar. The described interactions between life history ratios can also lead to $L_{\infty}$ being much higher than $L_{\max }$, an outcome that may seem surprising but is to be expected for species with high ratios of $M$ to $K$. This effect of the stepwise approach on the ratio of $M$ to $K$ was observed in our study: the groups with the highest ratios of $M$ to $K$ (groupers and sharks) had the greatest differences between the ratios of $L_{\text {mat }}$ to $L_{\infty}$ and of $L_{\text {mat }}$ to $L_{\text {Amax }}$. Subsequently, as in the study of Nadon and Ault (2016), we used the $L_{\text {mat }} \sim L_{\text {Amax }}$ relationship as the preferred model for obtaining $L_{\text {mat }}$. Our decision was further validated by $r^{2}$ values being higher when $L_{\text {Amax }}$ was used as the predictor than when $L_{\infty}$ was used.

To varying degrees, the relationships estimated with stepwise simulation in this study were similar to those established by Nadon and Ault (2016) with positive linear relationships between parameters in both the 
$L_{\infty} \sim L_{\max }$ and $L_{\text {mat }} \sim L_{\text {Amax }}$ pairs, negative curvilinear relationships between parameters in the $K \sim L_{\infty}$ pair, and a positive curvilinear relationship between parameters in the $M \sim K$ pair. The apparent outlier to this trend is a less positive, almost linear relationship between parameters in the $M \sim K$ pair for grunts that could be an effect of the small sample size $(n=9)$ for this taxonomic group. In this situation, the $K$ parameter contains limited information on $M$, but the relationship still defines the range of $M$ values that is likely for grunts. A similar situation was found for surgeonfishes and goatfishes by Nadon and Ault (2016).

The shark group had a large standard deviation in the $L_{\infty} \sim L_{\max }$ relationship. This difference was likely due to both the distribution of sizes for sharks and the decision to create the relationships for a taxonomic group broader than family. Our decision to group multiple families of sharks together was necessary because only one family of sharks, Carcharhinidae, had enough published life history information to generate family-specific relationships. We therefore extended the shark group in our study to comprise all families in the orders Carcharhiniformes and Lamniformes, which include most families of conservation concern, such as requiem (Carcharhinidae), hammerhead (Sphyrnidae), thresher (Alopiidae), mackerel (Lamnidae), and sand tiger (Odontaspididae) sharks. After comparing the relationships for only species of Carcharhinidae with the relationships for all species of Carcharhiniformes and Lamniformes, we determined that it was appropriate to use a model for all families in the orders Carcharhiniformes and Lamniformes, given the current lack of data for species not in Carcharhinidae. As more life history data become available, it would be appropriate to create more family-specific models for other shark families. Until then, we believe our approach provides a reasonable option to assess shark stocks in data-poor situations.

The average absolute percent difference in estimates of the SPR and of life history parameters from use of the stepwise approach and from life history studies for the 4 test species was only $19 \%$. This level of difference is similar to the $22 \%$ average difference found by Nadon and Ault (2016). The differences between estimates from stepwise simulation compared favorably with average differences of $59 \%$ and $44 \%$ for genus- and family-level estimates from use of the FishLife approach, respectively. The model proved most successful in estimating $L_{\infty}, L_{\text {mat }}$, and $M$, with an average absolute difference of only $8-11 \%$ between the stepwise estimates and those from life history studies. It is not entirely surprising that it was a struggle to estimate $L_{\infty}$ and $L_{\text {mat }}$ with the FishLife approach given that, in this approach, a local $L_{\max }$ estimate is not used within an $L_{\max } \sim L_{\infty}$ relationship to restrict $L_{\infty}$ and $L_{\text {mat }}$ estimates, as is done in the stepwise approach. The distributions of length parameter values estimated with the FishLife approach therefore effectively represent the range of values observed within a genus or family, a range that can be enormous (as evident in Figure 6). Wide distributions of length parameter values limit the utility of the FishLife approach to population assessment models, such as the length-based spawning potential ratio model (Hordyk et al., 2016), that can be parameterized with the ratios of $M$ to $K$ and of $L_{\text {mat }}$ to $L_{\infty}$. However, it is important to note that even these models will require a reasonable estimate of $L_{\infty}$ to scale the length data used to fit model parameters.

In addition, note that the distribution of these ratios can also be output from the stepwise simulation. It was a struggle to use our model to predict $K$, for which there was an average percent difference of $47 \%$ between the stepwise simulation and FishLife model, including the $124 \%$ difference for redbreasted wrasse $(K$ values were estimated with higher precision and accuracy when the FishLife approach was used; the $K$ parameter was the only one for which FishLife outperformed the stepwise approach in both metrics). These large discrepancies in estimation of the $K$ parameter did not have a strong effect on SPR estimation error because estimates of the SPR from use of the stepwise approach typically were within 0.05 of the value obtained from the relevant life history study.

The study described here has resulted in the extension of our capability to conduct stock assessments in datapoor situations to a greater number of species. Our stepwise approach is generally more precise and accurate than the FishLife approach, although more research comparing both approaches is certainly warranted. It is important to reiterate that these meta-analytical approaches are not meant to replace life history studies, which typically have well-designed spatial coverage, appropriate gear selection, large sample sizes, and peer-reviewed biological and statistical methods. We acknowledge that the stepwise approach presented here may introduce a large amount of uncertainty to any assessment relying on them, in comparison with a species- and location-specific life history study. The stepwise approach is meant to allow temporary assessments to be implemented. We highly recommend full integration of the uncertainty in estimates of life history parameters throughout any assessment. We also recommend that stock status and management metrics be viewed in a risk assessment context, in which greater uncertainty is directly related to more conservative management advice. Under these guidelines, predictions from the use of this approach have successfully been used to manage stocks in U.S. waters of the Pacific Ocean, passing independent expert reviews (Nadon and Ault, 2016; Nadon, 2019).

\section{Acknowledgments}

This study was part of the NOAA Ernest F. Hollings Undergraduate Scholarship Program, and we would like to thank the NOAA Office of Education and the NOAA Pacific Island Fisheries Science Center, Fisheries Research and Monitoring Division, for facilitating the research. A. Yau was integral in facilitating the visiting researcher. B. Taylor greatly improved the project with his expertise and professional advice. We thank J. O'Malley, B. Langseth, and 2 anonymous reviewers for their important feedback and comments on the manuscript. 


\section{Literature cited}

Al-Husaini, M., A. Al-Baz, S. Al-Ayoub, S. Safar, Z. Al-Wazan, and S. Al-Jazzaf.

2002. Age, growth, mortality, and yield-per-recruit for nagroor, Pomadasys kakaan, in Kuwait's waters. Fish. Res. 59(1):101-115. Crossref

Ault, J. S., J. A. Bohnsack, and G. A. Meester.

1998. A retrospective (1979-1996) multispecies assessment of coral reef fish stocks in the Florida Keys. Fish. Bull. 96:395-414.

Ault, J. S., S. G. Smith, J. Luo, M. E. Monaco, and R. S. Appeldoorn. 2008. Length-based assessment of sustainability benchmarks for coral reef fishes in Puerto Rico. Environ. Conserv. 35:221-231. Crossref

Ault, J. S., S. G. Smith, J. A. Browder, W. Nuttle, E. C. Franklin,

J. Luo, G. T. DiNardo, and J. A. Bohnsack.

2014. Indicators for assessing the ecological dynamics and sustainability of southern Florida's coral reef and coastal fisheries. Ecol. Indic. 44:164-172. Crossref

Berkson, J., and J. T. Thorson.

2015. The determination of data-poor catch limits in the United States: is there a better way? ICES J. Mar. Sci. 72:237-242. Crossref

Beverton, R. J. H., and S. J. Holt.

1959. A review of the lifespans and mortality rates of fish in nature, and their relation to growth and other physiological characteristics. In Ciba Foundation symposium - the lifespan of animals (colloquia on ageing), vol. 5 (G. E. W. Wolstenholme and M. O'Conner, eds.), p. 142-180. J. and A. Churchill Ltd., London.

Bolker, B. M.

2008. Ecological models and data in R, 408 p. Princeton Univ. Press, Princeton, NJ.

Charnov, E. L.

1993. Life history invariants: some explorations of symmetry in evolutionary ecology, 184 p. Oxford Univ. Press, Oxford, UK.

2008. Fish growth: Bertalanffy $k$ is proportional to reproductive effort. Environ. Biol. Fishes 83:185-187. Crossref

Charnov, E. L., and D. Berrigan.

1991. Evolution of life history parameters in animals with indeterminate growth, particularly fish. Evol. Ecol. 5:6368. Crossref

Chin, A., C. Simpfendorfer, A. Tobin, and M. Heupel.

2013. Validated age, growth and reproductive biology of Carcharhinus melanopterus, a widely distributed and exploited reef shark. Mar. Freshw. Res. 64:965-975. Crossref

Choat, J. H., and D. R. Robertson.

2002. Age-based studies. In Coral reef fishes: dynamics and diversity in a complex ecosystem (P. F. Sale, ed.), p. 57-80. Academic Press, San Diego, CA.

Craig, M. T., and P. A. Hastings.

2007. A molecular phylogeny of the groupers of the subfamily Epinephelinae (Serranidae) with a revised classification of the Epinephelini. Ichthyol. Res. 54:1-17. Crossref

Ellington, E. H., G. Bastille-Rousseau, C. Austin, K. N. Landolt,

B. A. Pond, E. E. Rees, N. Robar, and D. L. Murray.

2015. Using multiple imputation to estimate missing data in meta-regression. Methods Ecol. Evol. 6:153-163. Crossref

FAO.

2016. The state of world fisheries and aquaculture 2016: contributing to food security and nutrition for all, 200 p. FAO, Rome. [Available from website.]

Fenner, D.

2012. Challenges for managing fisheries on diverse coral reefs. Diversity 4:105-160. Crossref
Fox, J.

2008. Applied regression analysis and generalized linear models, 2nd ed., 688 p. Sage Publ., Thousand Oaks, CA.

Froese, R., and C. Binohlan.

2000. Empirical relationships to estimate asymptotic length, length at first maturity and length at maximum yield per recruit in fishes, with a simple method to evaluate length frequency data. J. Fish Biol. 56:758-773. Crossref

2003. Simple methods to obtain preliminary growth estimates for fishes. J. Appl. Ichthyol. 19:376-379. Crossref

Froese, R., and D. Pauly (eds.).

2017. FishBase. World Wide Web electronic publication, vers. 05/2017. [Available from website.]

Gedamke, T., and J. M. Hoenig.

2006. Estimating mortality from mean length data in nonequilibrium situations, with application to the assessment of goosefish. Trans. Am. Fish. Soc. 135:476-487. Crossref

Gilman, E., K. Passfield, and K. Nakamura.

2014. Performance of regional fisheries management organizations: ecosystem-based governance of bycatch and discards. Fish Fish. 15:327-351. Crossref

Goodyear, C. P.

1990. Spawning stock biomass per recruit: the biological basis for a fisheries management tool. ICCAT Collect. Vol. Sci. Pap. 32:487-497. SCRS/89/082. [Available from website.]

Heupel, M. R., D. M. Knip, C. A. Simpfendorfer, and N. K. Dulvy.

2014. Sizing up the ecological role of sharks as predators. Mar. Ecol. Prog. Ser. 495:291-298. Crossref

Hewitt, D. A., and J. M. Hoenig.

2005. Comparison of two approaches for estimating natural mortality based on longevity. Fish. Bull. 103:433-437.

Hilborn, R., and D. Ovando.

2014. Reflections on the success of traditional fisheries management. ICES J. Mar. Sci. 71:1040-1046. Crossref

Hoenig, J.

1983. Empirical use of longevity data to estimate mortality rates. Fish. Bull. 82:898-903.

Hordyk, A., K. Ono, K. Sainsbury, N. Loneragan, and J. Prince.

2015. Some explorations of the life history ratios to describe length composition, spawning-per-recruit, and the spawning potential ratio. ICES J. Mar. Sci. 72:204-216. Crossref

Hordyk, A. R., K. Ono, J. D. Prince, and C. J. Walters.

2016. A simple length-structured model based on life history ratios and incorporating size-dependent selectivity: application to spawning potential ratios for data-poor stocks. Can. J. Fish. Aquat. Sci. 73:1787-1799. Crossref

Hubble, $\mathrm{M}$

2003. The ecological significance of body size in tropical wrasses (Pisces : Labridae). Ph.D. diss., 182 p. James Cook Univ., Douglas, Australia. [Available from website.]

Jarić, I., and Z. Gačić

2012. Relationship between the longevity and the age at maturity in long-lived fish: Rikhter/Efanov's and Hoenig's methods. Fish. Res. 129-130:61-63. Crossref

Jensen, A. L.

1996. Beverton and Holt life history invariants result from optimal trade-off of reproduction and survival. Can. J. Fish. Aquat. Sci. 53:820-822. Crossref

1997. Origin of relation between $K$ and $L_{\text {inf }}$ and synthesis of relations among life history parameters. Can. J. Fish. Aquat. Sci. 54:987-989. Crossref

Jobling, M

1994. Fish bioenergetics, 310 p. Chapman and Hall, London.

Kronen, M., A. Vunisea, F. Magron, and B. McArdle.

2010. Socio-economic drivers and indicators for artisanal coastal fisheries in Pacific island countries and territories 
and their use for fisheries management strategies. Mar. Policy 34:1135-1143. Crossref

Lincoln, R., G. Boxhall, and P. Clark.

1982. A dictionary of ecology, evolution and systematics, 298 p. Cambridge Univ. Press, Cambridge, UK.

Ma, K. Y., and M. T. Craig.

2018. An inconvenient monophyly: an update on the taxonomy of the groupers (Epinephelidae). Copeia 106:443-456. Crossref

Nadon, M. O.

2017. Stock assessment of the coral reef fishes of Hawaii, 2016. NOAA Tech. Memo. NMFS-PIFSC-60, $212 \mathrm{p}$.

2019. Stock assessment of Guam coral reef fish, 2019. NOAA Tech. Memo. NMFS-PIFSC-82, 107 p.

Nadon, M. O., and J. S. Ault.

2016. A stepwise stochastic simulation approach to estimate life history parameters for data-poor fisheries. Can. J. Fish. Aquat. Sci. 73:1874-1884. Crossref

Nadon, M. O., J. S. Ault, I. D. Williams, S. G. Smith, and G. T. DiNardo.

2015. Length-based assessment of coral reef fish populations in the main and Northwestern Hawaiian Islands. PLoS ONE 10(8):e0133960. Crossref

Natanson, L. J., and B. M. Deacy.

2019. Using oxytetracycline validation for confirmation of changes in vertebral band-pair deposition rates with ontogeny in sandbar sharks (Carcharhinus plumbeus) in the western North Atlantic Ocean. Fish. Bull. 117:50-58. Crossref

Natanson, L. J., A. H. Andrews, M. S. Passerotti, and S. P. Wintner. 2018. History and mystery of age and growth studies in elasmobranchs. In Shark research: emerging technologies and applications for the field and laboratory (J. C. Carrier, M. R. Heithaus, and C. A. Simpfendorfer, eds.), p. 178-194. CRC Press, Boca Raton, FL.

Pardo, S. A., A. B. Cooper, and N. K. Dulvy.

2013. Avoiding fishy growth curves. Methods Ecol. Evol. 4:353-360. Crossref

Pauly, D.

1980. On the interrelationships between natural mortality, growth parameters, and mean environmental temperature in 175 fish stocks. ICES J. Mar. Sci. 39:175-192. Crossref

Prince, J., A. Hordyk, S. R. Valencia, N Loneragan, and K. Sainsbury. 2015. Revisiting the concept of Beverton-Holt life-history invariants with the aim of informing data-poor fisheries assessment. ICES J. Mar. Sci. 72:194-203. Crossref
$\mathrm{R}$ Core Team.

2017. R: a language and environment for statistical computing. R Foundation for Statistical Computing, Vienna, Austria. [Available from website, accessed May 2017.]

Raghunathan, T. E., J. M. Lepkowski, J. Van Hoewyk, and P. Solenberger.

2001. A multivariate technique for multiply imputing missing values using a sequence of regression models. Surv. Methodol. 27:85-95.

Rhodes, K. L., B. M. Taylor, and J. L. McIlwain.

2011. Detailed demographic analysis of an Epinephelus polyphekadion spawning aggregation and fishery. Mar. Ecol. Prog. Ser. 421:183-198. Crossref

Rudd, M. B., and J. T. Thorson.

2018. Accounting for variable recruitment and fishing mortality in length-based stock assessments for data-limited fisheries. Can. J. Fish. Aquat. Sci. 75:1019-1035. Crossref

Sebens, K. P.

1987. The ecology of indeterminate growth in animals. Annu. Rev. Ecol. Syst. 18:371-407. Crossref

Smith, W. L., and M. T. Craig.

2007. Casting the percomorph net widely: the importance of broad taxonomic sampling in the search for the placement of serranid and percid fishes. Copeia 1:35-55. Crossref

Symes, D., J. Phillipson, and P. Salmi.

2015. Europe's coastal fisheries: instability and the impacts of fisheries policy. Sociol. Rural. 55:245-257. Crossref

Then, A. Y., J. M. Hoenig, N. G. Hall, and D. A. Hewitt.

2015. Evaluating the predictive performance of empirical estimators of natural mortality rate using information on over 200 fish species. ICES J. Mar. Sci. 72:82-92. Crossref

Thorson, J. T.

2017. FishLife: predict life history traits for any fish. R package, vers. 1.0.2. [Available from website, accessed May 2020.]

Thorson, J. T., S. B. Munch, J. M. Cope, and J. Gao.

2017. Predicting life history parameters for all fishes worldwide. Ecol. Appl. 27:2262-2276. Crossref

van Buuren, $\mathrm{S}$.

2007. Multiple imputation of discrete and continuous data by fully conditional specification. Stat. Methods Med. Res. 16:219-242. Crossref

von Bertalanffy, L.

1938. A quantitative theory of organic growth (Inquiries on growth laws. II). Hum. Biol. 10:181-213. 